of a consistent theme could be problematic for a course taught within a specific department, such as Fisheries and Wildlife, or Urban Planning. On the other hand, the range of topics might be useful in a more general GIS course, where getting an idea of the possibilities of GIS within many subject areas is helpful.

Working through the modules was generally straightforward: they follow a pattern of presenting the scenario, identifying deliverables to support decision making within the scenario, documenting and setting up the project, performing analysis, and sharing your results. However, sometimes it was not clear whether it was ArcGIS Pro or ArcGIS Online that was to be used. The tight integration between ArcGIS Pro and ArcGIS Online-a feature of the software-meant that the line between the two was occasionally a little confusing.

There is an emphasis on raster rather than vector-based tools in the workbook modules, which may not be satisfying for those who rarely use remote sensing or raster data. Vector-based tools are covered, but they just don't receive as much emphasis and coverage as the raster tools. Overall, however, tool coverage is good, and nearly all the basic GIS toolsets are included: network analyst, spatial analyst, raster calculator, creating composite images from remote sensing data, lidar skills, supervised and unsupervised classification, and using LAS data to make DEMs.

There was a good deal of repetition built into the exercises, and this was welcome-repeated tool use helps the process sink in. Additionally, the modules encourage documentation of the process via note taking, which they list as a deliverable. This is a good practice generally and it was nice to see it promoted in this workbook. Some of the other writing assignments, such as writing an incident report in the first module, felt extraneous. It is clear that the writing assignments were included as part of the book's mission to teach about using tools to make decisions, and the writing is a reflection of the synthesis of decision making and information gathering, but sometimes the tasks did not hit their mark. Without an instructor to evaluate and critique the written deliverables, the value of the writing exercises is unclear: they could easily be an important part of a course that includes using ArcGIS Pro, but how do they teach you to use the software? Still, the writing assignments can be easily skipped.

Making Spatial Decisions Using ArcGIS Pro would make a good textbook for an introductory general GIS course. The depth of the modules and the wide range of assignments, which include writing prompts, are clear and follow a textbook style. The Esri Press summary for the book lists high school, community college, and university instructors and students as being the audience for the book. This seems reasonable, as the workbook would make a fine textbook for anyone getting started with ArcGIS Pro at many levels of education. It also works well as an introduction to ArcGIS Pro for a GIS professional outside of a class. There are other online tutorials and books that function similarly to this volume, but Making Spatial Decisions Using ArcGIS Pro: A Workbook is a solid contribution to the small pool of ArcGIS Pro learning resources.

\title{
TREASURES FROM THE MAP ROOM
}

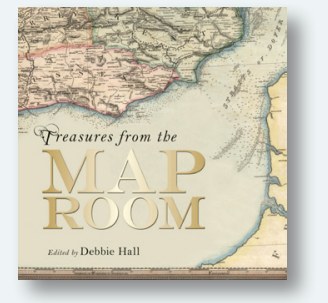

Edited by Debbie Hall

Bodleian Library, 2016

233 pages, \$60.00, hardcover.

ISBN: 978-1-85124-250-4

Review by: Marcy Bidney, University of

Wisconsin-Milwaukee

As the title suggests, Treasures from the Map Room is a book dedicated to showing us some of the treasures housed in the Bodleian Library map collections. The book is broken up into seven chapters, an Introduction, a List of Images and their sources, a nicely compiled bibliography, and an Index. The Introduction provides a brief history of the development of the Library's map collections, and each chapter focuses on a different type of map. These range from maps for travel and exploration, to maps of imaginary lands. Every chapter opens with an essay nicely tying together the topic with the maps and cartography. For example, the chapter on knowledge and science discusses how geographical knowledge was passed on through maps. There is a heavy bias toward British materials, both in the essays and the example maps, but that is only to be expected of a book focusing on the collections of the Bodleian. 
Highlights from the chapters include, in Chapter One ("Travel and Exploration"), an interesting comparison of two charts published by the Hydrographic Office of the Royal Navy showing the changes that occurred to the island of Krakatoa as a result of the catastrophic August 1883 volcanic eruption. Chapter Two brings us many excellent maps representing "Knowledge and Science." The standout example in this chapter come from the $1846 \mathrm{An}$ Historical Atlas in a Series of Maps of the World as known at different periods constructed upon an uniform scale and colored according to the political changes of the period by Edward Quin. Readers familiar with this atlas know that it is a series of maps, each showing a more extensive world, as, over time, it became known to Europeans. The known world on the maps is light and beautifully colored, while the "unknown" parts of the world are shrouded under a dark cloud called "terra incognita." The author of this map's description in Treasures from the Map Room rightfully tackles the absurd notion projected by this atlas that the world outside of the European context was "unknown" until discovered by Europeans. Chapter Three covers "Pride and Ownership," highlighting the idea that maps can show pride in ownership, either of a place itself or of a map depicting a place. The highlight of this chapter is the image of a small portion of a tapestry map showing part of Worcestershire. This tapestry is one of a set of four, each measuring about $15 \times 20$ feet! The tapestries were created to decorate a house - a rare idea in the late $16^{\text {th }}$ century.

In Chapter Four we find "Maps of War," which is a topic that cannot be ignored in a book such as this. The maps discussed show a variety of means for using maps in wartime. Of note in this chapter is the portion of a stunning map showing trenches along the front in World War One France. Chapter Five, "The City in Maps," shows the reader how cities have been mapped through the centuries. The real gem in this chapter is the panorama of London before the great fire, drawn by Dutch cartographer Claes Visscher. The details of buildings and in scenes of London life at the time are exquisite-seeing this one map in person should be on the bucket list of most map lovers. Chapter Six is all about "Maps for Fun" covering, for the most part, tourist maps. The standout in this chapter is the map of Yellowstone National Park in Wyoming. Its depiction of the park landscape, including the hot springs (viewed facing south from the Mammoth Hot Springs entrance), shows the park in its early years. Finally, in Chapter Seven we find maps of "Imaginary Lands" an interesting mix of maps of places that could have been, of places that were imagined to be, and of real places depicted as somehow symbolic.

The maps chosen to illustrate each of the chapter topics were thoughtfully chosen as representatives of the versatility and power that maps, and their meanings, can have. The reproductions are of high quality, and details are easily deciphered. When a map is too large to fit in its entirety on the page, either a well-chosen detail of the map is shown or the map is allowed to spill over onto the next page. Treasures from the Map Room successfully reaches its goal of showcasing the treasures of the map collections at the Bodleian Library at Oxford University with an interesting and thoughtful presentation. The reader gets a sense of each map and its historical importance, and a sense that the maps shown barely scratch the surface of the tremendous treasures to be found in the collections.

I would recommend Treasures from the Map Room for libraries who collect generally on cartographic history, or as a gift for lovers of maps and cartographic history.

\section{GIS TUTORIAL 1 FOR ARCGIS PRO}

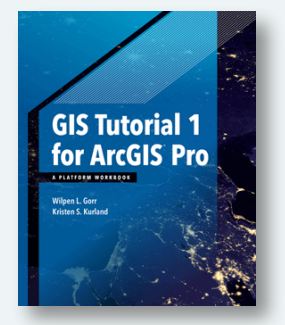

By Wilpen L. Gorr and Kristen S. Kurland

Esri Press, 2018

470 pages $\$ 99.99$, softcover.

ISBN: 978-1-58948-466-5

Review by: Tom Koch

\section{INTRODUCTION}

This latest instructional book from Esri Press is listed at \$99.99. Like its many predecessors, it serves three functions simultaneously. First, it seeks to teach the basic mechanics of an Esri software product, in this case ArcGIS Pro. Second, it seeks to sell Esri itself with the implicit message that GIS is Esri. Forget the many, and in some cases splendid, programs with first-rate instructional 